\title{
Determinants of Community-Acquired Pneumonia among Children Under-Five Years in Aswan, Egypt: Hospital-Based Case-Control Study
}

\author{
${ }^{1}$ Gehad Ahmed, ${ }^{2}$ Ghada S. T. Al-Attar, ${ }^{3}$ Magda F. Gabri, ${ }^{1}$ Shaimaa S. Abdelrheem \\ ${ }^{1}$ Public Health and Community Medicine Department, Faculty of Medicine, Aswan \\ University, Egypt. ${ }^{2}$ Public Health and Community Medicine Department, Faculty of \\ Medicine-Assiut University, Egypt. ${ }^{3}$ Pediatrics Department, Faculty of Medicine, Aswan \\ University, Egypt
}

Submission Date: 27-03-2021 Revision Date: 07-05-2021 Acceptance Date: 07-05-2021

\begin{abstract}
Background: Community-acquired pneumonia (CAP) plays a crucial role in under-five children's morbidity and mortality. The impact of CAP became more evident in Upper Egypt societies and has placed a substantial burden on already overburdened health and community services. Data on how CAP risk factors interact would be of great value and it could be addressed through preventive programs implemented to serve under-five children. Objective: This study identified the determinants for CAP in under-five children admitted to Aswan University Hospital. Method: A hospital-based, case-control study involving cases of pneumonia among children aged 2-59 months was conducted from August $1^{\text {st }}, 2019$ to August 31 ${ }^{\text {st }}, 2020$ at Aswan University Hospital, Egypt. The controls consisted of children admitted to the outpatient clinic in the same hospital for elective surgery. Children with any comorbidities were excluded. A multivariable regression analysis was performed including variables that were significant at $\mathrm{p}<0.05$ in the bivariate analysis. Results: The study evaluated 160 children in the case group and 160 children in the control group. Underweight $(\mathrm{OR}=17.18,95 \% \mathrm{CI}=4.35-37.64)$, current parental smoking $(\mathrm{OR}=9.54,95 \% \mathrm{CI}=2.80-32.41)$, mothers' knowledge score about CAP (moderate knowledge $\mathrm{OR}=2.23,95 \% \mathrm{CI}=1.25-9.46$, poor knowledge $\mathrm{OR}=6.11,95 \% \mathrm{CI}=1.46-8.08$ ) and when the distance to the nearest health center $>5$ kilometers $(\mathrm{OR}=4.70,95 \% \mathrm{CI}=1.3$ 16.24) were the significant predictors for CAP. Conclusion: Higher risk for progressing community-acquired pneumonia is associated with underweight, current parental smoking, poor score knowledge of mothers regarding CAP, and being at a distance $>5$ kilometers from the home to the closest health center.
\end{abstract}

Keywords:Case-control study, determinants, pediatric pneumonia, risk factors, under-five children.

Corresponding Author: Gehad Ahmed Email-address: gehad.a7med.gehad@gmail.com

\section{Introduction}

Despite the global progress in reducing under-five child mortality rates over the last few decades, an estimated 5.2 million children under age five died almost from preventable causes in 2019. ${ }^{1}$ Pneumonia remains the leading preventable cause of under-five children's morbidity and mortality, representing $15 \%$ of overall deaths. $^{2}$ Three quarters of pneumonia cases occur in developing countries. ${ }^{3}$
Egypt is one of the high burden settings where an estimated death rate of underfive pneumonia reaches $9.7 \%$ in $2016 .^{4}$

Pneumonia is being classified according to the setting in which it occurs as community-acquired or hospital-acquired. The term "community-acquired pneumonia" (CAP) is an infection acquired outside the hospital in a previously healthy child. The diagnosis is 
based on clinical features related to lower respiratory tract infection. ${ }^{5}$

In line with Egypt's Vision 2030 for Sustainable Development Strategy, many efforts are currently underway to improve health care for under-five children aiming to decrease under-five mortality by $50 \%$ in $2030 .^{6}$

CAP plays a crucial role in under-five children's morbidity and mortality. It has a significant burden on parents and on the health services in terms of time and expenses, making it a serious health problem in developing countries including Egypt. ${ }^{7}$ The impact of CAP became more evident in Upper Egypt societies and has placed a substantial burden on already overburdened health and community services. ${ }^{8,9}$

Indeed, few studies in Egypt have explored the determinants of pediatric pneumonia. Given the seriousness of CAP and variability of potential risk factors in under-five children, the current study intended to understand whether the studied factors could increase the vulnerability of previously healthy children to acquire pneumonia in one of Upper Egypt's health care settings.

Data on how CAP risk factors interact would be of great value and it could be tackled through incorporating preventive programs implemented to serve under-five children in Upper Egypt. Therefore, the objective of the present study was to identify the determinants for CAP in children under 5 years of age admitted to Aswan University Hospital, Aswan, Egypt.

\section{Method}

A hospital-based case-control study was conducted through the period from August $1^{\text {st }}, 2019$ to August $31^{\text {st }}, 2020$ at the pediatrics department in Aswan University Hospital (established in Upper Egypt in 2014 with the construction of faculty of medicine in Aswan governorate). Sample size calculation was done using open Epi Info ${ }^{\mathrm{TM}}$ program version 7.2.01 software, with the following parameters: estimated rate of $51.7 \%$ of children exposed to overcrowding in the control group, ${ }^{10} 80 \%$ statistical power to detect an odds ratio (OR) equal to 2.0, with an alpha error of 0.05 and a ratio of 1 case for 1 control. The obtained sample size was 150 cases and 150 controls. Due to possible dropout or refusal, the sample size was increased to 160 cases and 160 controls.

The study adopted total population sampling of eligible CAP cases during the data collection period. Children in either cases or controls were excluded if they had any primary comorbidities, such as heart, kidney, or liver disease; chronic lung disease; congenital lung malformation; neuropathy; hemoglobinopathies; immunodeficiency disorders.

The case group consisted of children aged 2 - 59 months admitted to Aswan University Hospital, with a clinical (cough and/or difficult breathing, with or without fever) and radiological diagnosis of CAP in accordance with the WHO diagnosis criteria: 1) fast breathing (respiratory rate $\geq 50$ breaths/minute if aged 2-11 months, and $\geq 40$ breaths/minute if aged $12-59$ months); 2) a lower chest wall indrawing where their chest moves in or retracts during inhalation (severe pneumonia); or 3) cyanosis and/or inability to feed or drink (very severe pneumonia) .2,11

The control group was composed of apparently healthy children who had been admitted to the outpatient clinic in the same studied hospital for elective surgery and did not have prior history or diagnosis of upper or lower respiratory diseases at the time of enrollment. Controls' selections were age and sex-matched.

Data collection and study tools:

Data was collected through face-to-face interviews with children's mothers using a semi-structured questionnaire. To 
minimize study biases and missing data, the study team collected data promptly

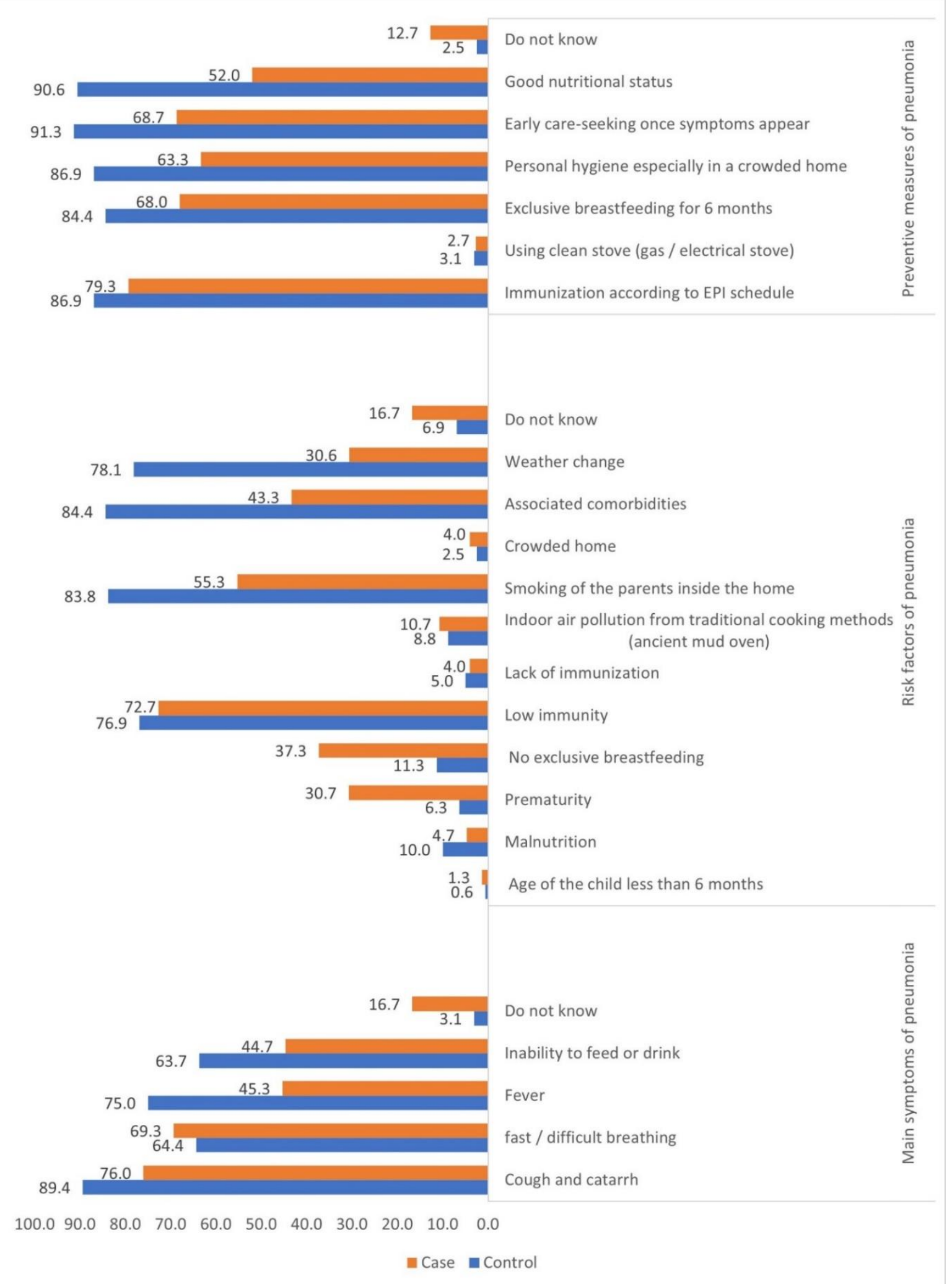

Figure (1) Mothers' knowledge about pneumonia among under-five children in Aswan, Egypt, 2019-2020

after the admission of each case. The questionnaire was divided into four sections: (1) Socio-demographic characteristics including maternal age,

\begin{tabular}{lllll}
\hline The Egyptian Journal of Community Medicine & Vol. 40 & No. 1 & January & 2022
\end{tabular}


parental education, parental occupation, residence, etc. (2) Child-related factors including age, gender, birth weight, Table (1) Socio-demographic factors of children under-five years in Aswan, Egypt, 2019-2020

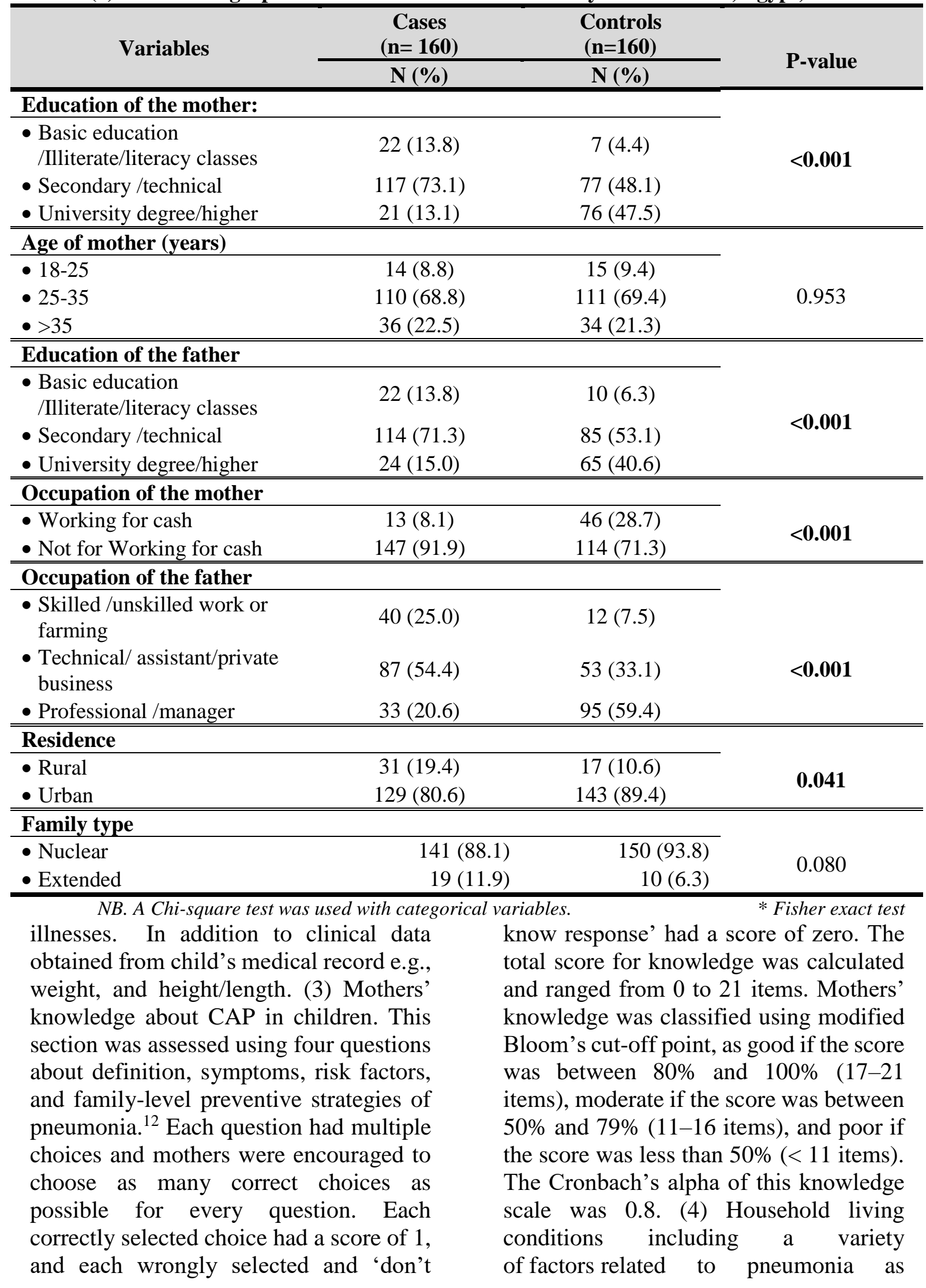


paternal smoking, household crowding, indoor air pollution, sunlight exposure, and the distance to the nearest health care facility. The questionnaire was revised by an expert pediatrician, and a pilot test of

Table (2) Child-related factors of children under-five years in Aswan, Egypt, 2019-2020

\begin{tabular}{|c|c|c|c|}
\hline \multirow{2}{*}{ Variables } & $\begin{array}{c}\text { Cases } \\
(n=160)\end{array}$ & $\begin{array}{l}\text { Controls } \\
(\mathrm{n}=160)\end{array}$ & \multirow{2}{*}{ P-value } \\
\hline & $\mathbf{N}(\%)$ & $\mathbf{N}(\%)$ & \\
\hline \multicolumn{3}{|l|}{ Weight for age (z score): ${ }^{\dagger}$} & \multirow{3}{*}{$<0.001$} \\
\hline$<-2$ z score & $76(47.5)$ & $18(11.2)$ & \\
\hline$\geq-2 \mathrm{z}$ score & $84(52.5)$ & $142(88.8)$ & \\
\hline \multicolumn{4}{|c|}{ Age of the child in a completed month: } \\
\hline Median (25th, 75th centile) & $12(3-30)$ & $12(3-30)$ & Matched \\
\hline \multicolumn{3}{|l|}{ Birth weight of the child: } & \multirow{3}{*}{0.132} \\
\hline$<2500$ gram & $25(15.6)$ & $16(10.0)$ & \\
\hline$\geq 2500$ gram & $135(84.4)$ & $144(90.0)$ & \\
\hline \multicolumn{3}{|l|}{ Exclusive breastfeeding: } & \multirow{3}{*}{$0.001 *$} \\
\hline Yes & $144(91.3)$ & $158(98.8)$ & \\
\hline No & $16(8.8)$ & $2(1.3)$ & \\
\hline \multicolumn{3}{|l|}{ Birth order of the child } & \multirow{4}{*}{$<0.001$} \\
\hline $1^{\text {st }}$ Order & $29(18.1)$ & $63(39.4)$ & \\
\hline $2 \mathrm{nd}$ or $3^{\text {rd }}$ & $106(66.3)$ & $85(53.1)$ & \\
\hline 4th or more & $25(15.6)$ & $12(7.5)$ & \\
\hline \multicolumn{3}{|l|}{ Daycare attendance: } & \multirow{3}{*}{$<0.001$} \\
\hline Yes & $15(9.4)$ & $50(31.3)$ & \\
\hline No & $145(90.6)$ & $110(68.8)$ & \\
\hline
\end{tabular}

Direct contact between child and persons with upper respiratory tract

infection last days:

$\begin{array}{lrr}\text { Yes } & 39(24.4) & 18(11.3) \\ \text { No } & 121(75.6) & 142(88.8)\end{array}$

0.002

History of lower respiratory tract infections (bronchiolitis /pneumonia) in the last year:

\begin{tabular}{|c|c|c|c|}
\hline Yes & $60(375)$ & $104(650)$ & $<0.001$ \\
\hline No & $100(62.5)$ & $56(35.0)$ & \\
\hline \multicolumn{3}{|c|}{ Admission to the hospital last year diagnosed with pneumonia: * } & \multirow{3}{*}{0.044} \\
\hline Yes & $26(43.3)$ & $29(27.9)$ & \\
\hline No & $34(56.7)$ & $75(72.1)$ & \\
\hline \multicolumn{3}{|c|}{ Proper immunization according to EPI: } & \multirow{3}{*}{0.186} \\
\hline Yes & $150(93.8)$ & $155(96.9)$ & \\
\hline No & $10(6.3)$ & $5(3.1)$ & \\
\hline \multicolumn{3}{|c|}{ Antenatal care during pregnancy: } & \multirow{3}{*}{0.102} \\
\hline Yes & $143(89.4)$ & $151(94.4)$ & \\
\hline No & $17(10.6)$ & $9(5.6)$ & \\
\hline
\end{tabular}

NB. A Chi-square test was used with categorical variables. * Fisher exact test. $\dagger$ Nutritional status (weight for age) was classified according to WHO child growth standards using the -2 Z-score cutoff point into a very low/ low weight for age and normal weight for age, Z score calculation was done through WHO anthro. ${ }^{45}$ the result includes $100 \%$ of those selected in the preceding variable.

the questionnaire $(\mathrm{n}=30)$ was applied. The study tool was sufficiently clear, and no adjustment was needed. Pilot study participants were not excluded from the main work.

\begin{tabular}{lllll}
\hline The Egyptian Journal of Community Medicine & Vol. 40 & No. 1 & January & 2022
\end{tabular} 


\section{Statistical analysis}

The collected data were coded and entered using IBM SPSS software

Table (3): Household living conditions of children under-five years in Aswan, Egypt, 20192020

\begin{tabular}{|c|c|c|c|}
\hline \multirow[t]{2}{*}{ Variable } & $\begin{array}{c}\text { Cases } \\
(\mathbf{n}=\mathbf{1 6 0})\end{array}$ & $\begin{array}{c}\text { Controls } \\
(n=160)\end{array}$ & \multirow{2}{*}{ P-value } \\
\hline & $\mathbf{N}(\%)$ & $\mathbf{N}(\%)$ & \\
\hline \multicolumn{3}{|c|}{ Smoking of the parents } & \multirow{3}{*}{$<0.001$} \\
\hline Yes & $104(65.0)$ & $36(22.5)$ & \\
\hline No & $56(35.0)$ & $124(77.5)$ & \\
\hline \multicolumn{3}{|c|}{ The distance between the home and the nearest health center } & \multirow{3}{*}{$<0.001$} \\
\hline$\leq 5$ kilometers & $71(44.4)$ & $106(66.3)$ & \\
\hline$>5$ kilometers & $89(55.6)$ & $54(33.8)$ & \\
\hline \multicolumn{3}{|c|}{ Household crowding (>7 people in the household) $\S$} & \multirow{3}{*}{ 0.011* } \\
\hline Yes & $13(8.1)$ & $3(1.9)$ & \\
\hline No & $147(91.9)$ & $157(98.1)$ & \\
\hline \multicolumn{3}{|l|}{ Exposure to sunlight } & \multirow{3}{*}{0.025} \\
\hline Yes & $76(47.5)$ & $96(60.0)$ & \\
\hline No & $84(52.5)$ & $64(40.0)$ & \\
\hline \multicolumn{3}{|c|}{ Exposure time to sunlight last month\| } & \multirow{3}{*}{$<0.001$} \\
\hline$\geq 30$ minutes & $51(67.1)$ & $86(89.6)$ & \\
\hline$<30$ minutes & $25(32.8)$ & $10(10.4)$ & \\
\hline \multicolumn{3}{|c|}{ Availability of ancient mud oven: } & \multirow{3}{*}{0.018} \\
\hline Yes & $27(16.9)$ & $13(8.1)$ & \\
\hline No & $133(83.1)$ & $147(91.9)$ & \\
\hline \multicolumn{3}{|c|}{ Smoke factories in surroundings } & \multirow{3}{*}{$0.006 *$} \\
\hline Yes & $10(6.3)$ & $1(0.6)$ & \\
\hline No & $150(93.8)$ & $159(99.4)$ & \\
\hline \multicolumn{3}{|c|}{ Agricultural farms in the surroundings: } & \multirow{3}{*}{0.001} \\
\hline Yes & $29(18.1)$ & $10(6.3)$ & \\
\hline No & $131(81.9)$ & $150(93.8)$ & \\
\hline \multicolumn{3}{|c|}{ Poultry in the house: } & \multirow{3}{*}{0.028} \\
\hline Yes & $31(19.4)$ & $17(10.6)$ & \\
\hline No & $129(80.6)$ & $143(89.4)$ & \\
\hline
\end{tabular}

NB. A Chi-square test was used with categorical variables. * Fisher exact test. ${ }^{\S}$ The household crowding index was defined as more than seven persons per household. ${ }^{30} \|$ The results include $100 \%$ of those selected (yes) in the preceding variable.

statistics were computed for all variables. Qualitative variables were presented in frequency and percentages. For quantitative variables, mean and standard deviation were calculated for normally distributed variables; and median (25th, 75th centile) for not normally distributed variables. Inferential statistics were performed; Chi-Square was used for the analysis of categorical data. Whenever
(SPSS forWindows, version 26.0, SPS

SInc., Chicago, IL, USA). Descriptive 
The Ethics Review Committee of Aswan Faculty of Medicine approved the study and the head of the pediatrics department gave his official approval as well. Verbal consent was obtained from the children's

Table (4) Pooled regression model of determinants of community-acquired pneumonia among children under-five years in Aswan, Egypt, 2019-2020

\begin{tabular}{|c|c|c|c|c|}
\hline \multirow{2}{*}{ Variable } & \multirow{2}{*}{$\begin{array}{c}\text { Adjusted } \\
\text { OR }\end{array}$} & \multirow{2}{*}{ P-value } & \multicolumn{2}{|c|}{ 95\% C.I. } \\
\hline & & & Lower & Upper \\
\hline $\begin{array}{l}\text { Weight for age (z score): }(\text { Ref }=\geq-2 \text { z score }) \\
<-2 \text { z score }\end{array}$ & 17.18 & 0.001 & 4.35 & 37.64 \\
\hline $\begin{array}{l}\text { Smoking of the parents: }(\text { Ref }=\text { No }) \\
\text { Yes }\end{array}$ & 9.54 & $<0.001$ & 2.80 & 32.41 \\
\hline $\begin{array}{l}\text { Mothers' knowledge score about CAP: }(\text { Ref }=\text { Good } \\
\text { knowledge) } \\
\text { Moderate knowledge } \\
\text { Poor knowledge } \\
\end{array}$ & $\begin{array}{l}2.23 \\
6.11 \\
\end{array}$ & $\begin{array}{l}\mathbf{0 . 0 0 1} \\
0.017 \\
0.001 \\
\end{array}$ & $\begin{array}{l}1.25 \\
1.46 \\
\end{array}$ & $\begin{array}{l}9.46 \\
8.08 \\
\end{array}$ \\
\hline $\begin{array}{l}\text { The distance between the home and the nearest } \\
\text { health center: (Ref }=\leq 5 \text { kilometers) } \\
>5 \text { kilometers }\end{array}$ & 4.70 & 0.014 & 1.36 & 16.24 \\
\hline $\begin{array}{l}\text { Exposed time to sunlight last month: }{ }^{\mathbb{I}}(\text { Ref }=\geq \mathbf{3 0} \\
\text { minutes) } \\
<30 \text { minutes }\end{array}$ & 4.65 & 0.113 & 0.69 & 13.25 \\
\hline $\begin{array}{l}\text { Education of the mother: (Ref }=\text { University } \\
\text { degree/higher) } \\
\text { Illiterate/ literacy classes /Basic education } \\
\text { Secondary /technical }\end{array}$ & $\begin{array}{l}4.19 \\
1.89\end{array}$ & $\begin{array}{l}0.317 \\
0.370\end{array}$ & $\begin{array}{l}1.25 \\
1.46\end{array}$ & $\begin{array}{c}16.46 \\
7.70\end{array}$ \\
\hline $\begin{array}{l}\text { Occupation of the mother: }(\text { Ref }=\text { not Working for } \\
\text { cash) } \\
\text { Working for cash }\end{array}$ & 0.33 & 0.248 & 0.05 & 2.13 \\
\hline $\begin{array}{l}\text { Occupation of the father: (Ref }=\text { professional } \\
\text { /manager) } \\
\text { Skilled /unskilled work or farmer } \\
\text { Technical/ assistant/private business }\end{array}$ & $\begin{array}{l}2.51 \\
4.01\end{array}$ & $\begin{array}{l}0.335 \\
\mathbf{0 . 0 3 6}\end{array}$ & $\begin{array}{l}0.38 \\
1.09\end{array}$ & $\begin{array}{l}16.41 \\
14.64\end{array}$ \\
\hline $\begin{array}{l}\text { Admission to the hospital last year diagnosed with } \\
\text { pneumonia: } * *(\text { Ref }=\text { No }) \\
\text { Yes }\end{array}$ & 2.27 & 0.195 & 0.65 & 7.90 \\
\hline Agricultural Farms in the surroundings: $($ Ref $=$ No $)$ & & & & \\
\hline Yes & 1.06 & 0.950 & 0.13 & 8.53 \\
\hline Constant & & 0.000 & & \\
\hline
\end{tabular}

"includes who was exposed to the sun last month. ${ }^{* *}$ includes who had pneumonia last year. Knowledge score above $80 \%$ is considered "good", "moderate" if the score was between 50 and $79 \%$ and below $50 \%$ as "poor". interview, CAP cases were advised about preventive measures and how to follow their treatment.

\section{Results}

The study included 320 children: 160 cases and 160 controls. The median age mothers after they were informed about the objectives of the study. Confidentiality and privacy of the data were assured. At the end of each 
Aswan city. The mean hemoglobin level of cases was 9.95 \pm 1.29 .

Concerning mother's knowledge about pneumonia, all mothers $(100.0 \%)$ heard about pneumonia, however, lack of mother's knowledge was evident among mothers of cases' group as shown in figure (1). The total score of Mothers' knowledge about CAP was $8.4 \pm 3.97$ among cases vs. $14.93 \pm 4.41$ among controls ( $\mathrm{p}<0.001)$.

The bivariate analysis indicated that sociodemographic variables such as maternal education, paternal education, father occupation, mother occupation, and rural residence were associated with CAP in the children table (1).

CAP was significantly associated with underweight (low/very low weight for age), lack of exclusive breast-feeding, high birth order, day-care attendance, history of direct contact with a person infected with upper respiratory tract, and history of hospital admission with pneumonia as shown in table (2). However, there was no significant association between CAP and immunization status or antenatal care attendance.

Regarding household living conditions, all the studied variables in table (3) were found to be significantly associated with CAP.

Binary logistic regression models were fitted one after the other. Significant variables at the bivariate level were mainly included in the primary models. The pooled model contained all significant variables in the primary models. Table (4) demonstrates the significant predictors for CAP in the final model, in which the underweight $(\mathrm{OR}=17.18,95 \% \mathrm{CI}=4.35-37.64)$, current parental smoking $(\mathrm{OR}=9.54, \quad 95 \%$ $\mathrm{CI}=2.80-32.41$ ), mothers' knowledge score about CAP (moderate knowledge $\mathrm{OR}=2.23,95 \% \mathrm{CI}=1.25-9.46$, poor knowledge $\mathrm{OR}=6.11,95 \% \mathrm{CI}=1.46-8.08$ ) and distance to the nearest health center >
5 kilometers $(\mathrm{OR}=4.70,95 \% \mathrm{CI}=1.3$ 16.24) were the significant predictors.

\section{Discussion}

Most of the conditions related to CAP in under-five children are mainly preventable and modifiable factors., ${ }^{2,13}$ To implement preventive measures, it is necessary to detect determinants for this type of pneumonia at first.

The current study revealed that low maternal education (not getting a university degree) was associated with CAP. This was consistent with the findings of earlier studies which showed that maternal education was inversely related to the incidence of pneumonia. ${ }^{14-}$ 17 Indeed, this is attributed to the level of maternal knowledge about pneumonia. ${ }^{18}$ Well-educated mothers can identify the disease and seek care as early as possible, ${ }^{17}$ as well as provide more care for their children. ${ }^{19}$ Inversely, low paternal education may hinder understanding the severity of the disease and how to use health services. ${ }^{20}$ However, in the current study, the association became insignificant in the pooled model. Similarly, a case-control study conducted in Alexandria, found that the association between pneumonia and low maternal education failed to continue within the final model. ${ }^{21}$

According to some studies, there is no relationship between mother's or father's occupation and CAP in Egyptian children, ${ }^{17,21}$ and Kenyan children. ${ }^{15}$ Similarly, mother's work was not a significant predictor in the final model of the current study. A Brazilian study observed that children whose mothers work outside the home were more likely to have children with CAP. ${ }^{22}$ On the other hand, this variable was a protective factor against lower respiratory tract infections (LRTI) in Brazil. ${ }^{23}$ Working mothers may influence the family income and socioeconomic status. In Egyptian 
children, low family income was found to be associated with severe LRTI. ${ }^{17}$

On the other hand, the regression analysis found that children whose parents work in skilled /unskilled work or farming were four times more to get pneumonia compared to children whose parents work in higher jobs. This finding was in agreement with a study that was conducted in Tanzania. ${ }^{24}$ The family's income and, as a result, the household living conditions are influenced by the work type. Low-wage employment eventually became a risk factor for pneumonia because it leads to the use of unsanitary cooking practices, indoor air pollution, and food inaccessibility, and resulting in childhood malnutrition. ${ }^{24}$

In agreement with a study that was conducted in Egypt by Azab et al., ${ }^{17}$ the current study exhibited a significant association between rural residence and occurrence of CAP cases in the bivariate analysis, but this association became insignificant in multivariable analysis. Most of the studied children resided in Aswan city, the location of the studied hospital at the time. Regardless, the difference seen between rural and urban areas was explained by the access pattern to health services, socioeconomic living conditions, and type of education. ${ }^{17} \mathrm{In}$ Assiut's study, there was no significant association between rural residence and CAP. ${ }^{9}$ Inconsistently, the urban residence was found to be a risk factor for CAP cases in children under the age of five in Finland. ${ }^{25}$

The current study found that underweight was the highest significant predictor of community-acquired pneumonia in the final regression model.

Several studies have found a significant association between being underweight and the development of pediatric pneumonia. ${ }^{24,26}$ Undernutrition impairs the immune system and its functions making the child more prone to infections and by the same way infections lead to undernutrition. ${ }^{27}$ Contrary to the current results, a Brazilian case-control study found no significant association between underweight and pneumonia. ${ }^{19}$

Unlike previous studies that reported a significant association between CAP and lack of exclusive breastfeeding. ${ }^{18,28,29}$ The current study and two other studies revealed no significant association between CAP cases and exclusive breastfeeding. ${ }^{15,19}$

High birth order of 4 or more was reported as a risk factor for pneumonia incidence among children. ${ }^{21}$ Contrarywise, the current study did not find any significant association in multivariable analysis. A large number of children in a family makes it difficult to provide appropriate care to them, resulting in household crowding, which is a definite risk factor for pneumonia. ${ }^{21}$

In agreement with other Egyptian studies, it was also observed that daycare attendance was not associated with pneumonia. $^{30,31}$ This could be explained by the fact that the time spent in the daycare centers was limited, limiting the chance for more contact. ${ }^{32}$

Indeed, incomplete vaccination was identified as a significant predictor for under-five CAP. ${ }^{18}$ In contrary to these results and consistent with another casecontrol study, ${ }^{15}$ we found no significant association between CAP and incomplete vaccination. In the current study, 93.8\% of children among the case group have been immunized properly according to EPI versus $96.9 \%$ of children among the control group, and this was in agreement with the percentage of coverage of EPI in Egypt which was over $90 \% .{ }^{33}$

In the present study, consistent with the results of Rashad et al., ${ }^{34}$ it was found that the mean hemoglobin level among pneumonic studied children was low $(9.95 \pm 1.296$ and $9.5 \pm 1.1$ respectively). This can be explained by the fact that low hemoglobin level hinders the oxygen delivery leading to poor tissue 
oxygenation in the lungs. ${ }^{5}$

In line with several studies that investigated the effect of mothers' knowledge on pneumonia incidence, ${ }^{35-37}$ the study recognized low maternal knowledge as a significant predictor for the incidence of pneumonia in under-five children. When mothers fail to understand the seriousness of the disease, many children with pneumonia are unable to receive health services at the right time. ${ }^{12}$ It is affirmed that under-five mortality can be reduced by identifying CAP symptoms and signs by the mothers at the earliest. ${ }^{38}$ Hence, a good mother's knowledge may reduce the occurrence of pneumonia in under-five children. Strengthening the family's capability to identify danger signs has been supported by the WHO and UNICEF. ${ }^{39}$ Awareness should be provided across mass media, so many invaluable lives can. be protected.

Current parental smoking increases the odds of CAP incidence by 9.5 folds in our study. This finding was consistent with previous studies in different countries including Egypt which have revealed that current parental smoking increases the incidence of pneumonia in children. ${ }^{16,21,30}$ Current parental smoking leads to respiratory infections especially for their children because the immune system is not fully developed in the children. Moreover, exposure to passive smoking damages the epithelium, increases the probability of pathogens adherence to the respiratory tract epithelium, and impairs protective mechanism such as mucociliary clearance. ${ }^{20}$

The current study and Onyango et al study, ${ }^{15}$ found that long-distance $>5$ kilometers from the home to the nearest health center was a significant determinant for CAP $(\mathrm{OR}=4.7$, and $\mathrm{OR}=1.80$ respectively). Long-distance to health care services was the main challenge to children receiving care. ${ }^{40}$ Contrary to what is proved that there is a significant association between household crowding and incidence of childhood pneumonia. ${ }^{21,41}$ The current study and Ngocho et al. ${ }^{24}$ found no significant associations between CAP in under-five children and household crowding. This was explained by the fact that general crowding is not a significant factor in the incidence of pneumonia, or that crowding is so standardized that it cannot be classified as the main predictor of pneumonia in a case-control study. ${ }^{42}$

Exposure to the sun for less than 30 minutes per day was significantly associated with the incidence of underfive pneumonia in New Zealand. ${ }^{26}$ This finding was observed in our primary regression model only. Another research in Cairo found no evidence of an association between childhood sun exposure and pneumonia. ${ }^{43}$ Spending more time outside decreases the time that would be spent inside the home, consequently decrease the exposure to other environmental factors as dampness, indoor air pollution, and household crowding. ${ }^{26}$ Also, less sun exposure decreases vitamin D level which is associated with pneumonia incidence. ${ }^{44}$ Overall, results from the study setting, indicated that most CAP determinants could be avoided. When the present results were compared with the findings of previous studies, it was clear that most of the classical risk factors were included in the sample population. Still, additional risk factors should be investigated in new etiological studies.

\section{Conclusion and recommendation}

From the potential determinants of community-acquired pneumonia that were investigated in the current study, the study identified higher risk for progressing to CAP in under-five children is associated specifically with underweight, current parental smoking, poor score knowledge of mothers regarding CAP, and distance more than 5 
kilometers from the home to the closest health center.

As a result, health care consultants should collaborate with community members to improve child nutritional status, raise awareness about the effects of parental smoking and urge parents to stop, and educate mothers about the symptoms, risk factors, and family-level pneumonia preventive measures. Moreover, equipping all areas with qualified health centers will result in a reduction in complicated cases and the ability to initiate care before cases need hospital admission. Overall, they can play a significant role in reducing CAP in upper Egypt.

Limitations of the study: The hospitalbased nature of the study could limit the generalizability of the findings. Casecontrol studies, in general, may be subject to recall biases. The other limitations were related to incomplete data of almost all hospital records. Some parameters such as hemoglobin level were not available in all participants and their role might be underestimated. It was difficult to assess the role of lab markers in pneumonia incidence among children such as serum zinc, Vitamin D levels as few lab investigations were performed for the outpatient sample.

\section{References}

1. World Health Organization. Children: improving survival and well-being. Geneva: World Health Organization; 2020. (updated September 8, 2020). Available from: https://www.who.int/news-room/factsheets/detail/children-reducing-mortality. Accessed December 21, 2020.

2. World Health Organization. Pneumonia. Geneva; World Health Organization; 2019. (updated 2 August 2019). Available from: https://www.who.int/news-room/factsheets/detail/pneumonia. Accessed December 14, 2020.
3. Wardlaw TM, Johansson EW, Hodge MJ. Pneumonia: the forgotten killer of children. UNICEF; 2006.

4. World Health Organization. Child and adolescent health. Geneva: World Health Organization; 2017. Available from: http://www.emro.who.int/childadolescent-health/data-statistics/ egypt.html. Accessed December 21, 2020. 5. Harris M, Clark J, Coote N, Fletcher P, Harnden A, McKean M, Thomson A. British Thoracic Society guidelines for the management of community acquired pneumonia in children: update 2011. Thorax. 2011 Oct 1;66(Suppl 2):ii1-23.

6. El-Megharbel N. Sustainable development strategy: Egypt's vision 2030 and planning reform. Retrieved, November. 2015.

7. Montasser N, Helal R, Rezq R. Assessment and Classification of Acute Respiratory Tract Infections among Egyptian Rural Children. Journal of Advances in Medicine and Medical Research 2012;2(2):216-227. doi:10.9734/bjmmr/2012/1038.

8. El-Saied MM, Mohie El Deen ZM, Askar GA, Shaker GS, Hamed EA. Recurrent Pneumonia in Children Admitted to Assiut University Children Hospital. Magnitude of the Problem and Possible Risk Factors. Medical Research Journal 2019;4(1):13-24. doi:10.5603/mrj. a2019.0001.

9. Hamed A., Kassem Y, Fayed H, Solaiman A. Serum zinc levels in hospitalized children with pneumonia: a hospital-based case-control study. Egyptian Journal of Bronchology 2019;13(5):730. doi:10.4103/ejb.ejb_30_19.

10. El Basha N, Mohsen M, Kamal M, Mehaney D. Association of vitamin D deficiency with severe pneumonia in hospitalized children under 5 years. Comp Clin Path 2014;23(5):1247-1251. doi:10.1007/s00580-013-1770-0.

11. World Health Organization. Pocket book of hospital care for children: 
guidelines for the management of common childhood illnesses Second Edition. World Health Organization; 2013. 12. Abusaad FE, Hashem SF. Mothers' learning needs assessment regarding pneumonia among children less than five years at Saudi Arabia. J Res Nurs Midwifery 2014;3(5):85-93. doi:10.14303/JRNM.2014.020

13. UNICEF. Pneumonia in Children. UNICEF; 2020. (updated October 2020). Available from: https://data.unicef.org/ topic/child-health/pneumonia/ Accessed December 15, 2020.

14. González-Coquel S, EscamillaArrieta J, Coronell-Rodriguez W, Salcedo-Mejía F, Alvis-Guzmán N. Severity factors of Acquired Pneumonia Community in a children's hospital in the Colombian Caribbean 2018;34(2):302314.

15. Onyango D, Kikuvi G, Amukoye E, Omolo J. Risk factors of severe pneumonia among children aged 2-59 months in western Kenya: A case control study. Pan Afr Med J 2012; 13:1-13. doi:10.11604/pamj.2012.13.45.1733.

16. Le Roux DM, Myer L, Nicol MP, Zar HJ. Incidence and severity of childhood pneumonia in the first year of life in a South African birth cohort: The Drakenstein Child Health Study. Lancet Glob Heal 2015;3(2): e95-e103. doi:10.1016/S2214-109X (14)70360-2.

17. Azab SF, Sherief LM, Saleh SH, Elsaeed WF, Elshafie MA, Abdelsalam SM. Impact of the socioeconomic status on the severity and outcome of community-acquired pneumonia among Egyptian children: A cohort study. Infect Dis Poverty 2014;3(1):1-7. doi:10.1186/2049-9957-3-14.

18. Arshad I, Khalid S, Khan S, Bashir S, Waseem H, Naveed $M$. Community acquired pneumonia and demographic factors: A cross sectional study. J Fatima Jinnah Med Univ 2019;(13):83-86.
19. da Fonseca Lima EJ, Mello MJ, Lopes MI, Serra GH, Lima DE, Correia JB. Risk factors for community-acquired pneumonia in children under five years of age in the post-pneumococcal conjugate vaccine era in Brazil: A case control study. BMC Pediatr 2016;16(1):1-9. doi:10.1186/s12887-016-0695-6.

20. Ramezani M, Aemmi SZ, Moghadam ZE. Factors affecting the rate of pediatric pneumonia in developing countries: A review and literature study. Int J Pediatr 2015;3(6.2):1173-1181. doi:10.22038/ijp.2015.6179.

21. Fadl N, Ashour A, Muhammad YY. Pneumonia among under-five children in Alexandria, Egypt: a casecontrol study. J Egypt Public Health Assoc 2020;95(1). doi:10.1186/s42506020-00043-0.

22. Fonseca W, Kirkwood BR, Victora CG, Fuchs SR, Flores JA, Misago C. Risk factors for childhoood pneumonia among the urban poor in Fortaleza, Brazil: A case-control study. Bull World Health Organ 1996;74(2):199-208.

23. Macedo SEC, Menezes AMB, Albernaz E, Post P, Knorst M. Risk factors for acute respiratory disease hospitalization in children under one year of age. Rev Saude Publica 2007;41(3):351-358. doi:10.1590/s003489102007000300005.

24. Ngocho JS, de Jonge MI, Minja L, Olomi GA, Mahande MJ, Msuya SE, Mmbaga BT. Modifiable risk factors for community-acquired pneumonia in children under 5 years of age in resourcepoor settings: a case - control study. Trop Med Int Heal J 2019;24(4):484-492. doi:10.1111/tmi.13211.

25. Heiskanen-Kosma T, Korppi M, Jokinen C, Heinonen K. Risk factors for community-acquired pneumonia in children: a population-based case-control study. Scandinavian journal of infectious diseases 1997 Jan 1;29(3):281-5.

26. Grant CC, Emery D, Milne T, Coster G, Forrest CB, Wall CR, et al. Risk 
factors for community-acquired pneumonia in pre-school-aged children. Journal Paediatrics and Child Health 2012;48(5):402-412. doi:10.1111/j.14401754.2011. 02244.x.

27. Schlaudecker EP, Steinhoff MC, Moore SR. Interactions of diarrhea, pneumonia, and malnutrition in childhood: recent evidence from developing countries. Current opinion in infectious diseases $2011 \quad$ Oct;24(5):496. doi:10.1097/QCO.0b013e328349287d.

28. César JA, Victora CG, Barros FC, Santos IS, Flores JA. Impact of breast feeding on admission for pneumonia during postneonatal period in Brazil: Nested case-control study. $\mathrm{Br}$ Med J 1999;318(7194):1316-1320.

doi:10.1136/bmj.318.7194.1316.

29. Lamberti LM, Zakarija-Grković I, Walker CL, Theodoratou E, Nair H, Campbell $\mathrm{H}$, et al. Breastfeeding for reducing the risk of pneumonia morbidity and mortality in children under two: A systematic literature review and metaanalysis. BMC Public Health 2013;13(3). doi:10.1186/1471-2458-13-S3-S18

30. Jackson S, Mathews KH, Pulanić D, Falconer R, Rudan I, Campbell H, et al. Risk factors for severe acute lower respiratory infections in children - a systematic review and meta-analysis. Croatian medical journal 2013;54(2):110121. doi:10.3325/cmj.2013.54.110.

31. El Sakka AS, Imam SS, Amer HA, Moustafa SA. Vitamin D deficiency and low hemoglobin level as risk factors for severity of acute lower respiratory tract infections in Egyptian children: A casecontrol study. Egyptian Pediatric Association Gazette 2014;62(1):1-7. doi: 10.1016/j.epag.2013.12.001.

32. Martins AL, Nascimento DD, Schneider IJ, Schuelter-Trevisol F. Incidence of community-acquired infections of lower airways among infants. Revista Paulista de Pediatria 2016 Jun;34(2):204-9. doi: 10.1016/j.rppede.2015.10.005.
33. World Health Organization. Expanded Programme on Immunization Programmes | Egypt. Geneva: World Health Organization; 2020. Available from;

http://www.emro.who.int/egy/programm es/expanded-programme-onimmunization.html. Accessed December 14, 2020.

34. Rashad M, Fayed S, El-Hag AM. Iron-deficiency anemia as a risk factor for pneumonia in children. Benha Medical Journal 2015;32(2):96. doi:10.4103/1110-208x.180321.

35. Ekure EN, Esezobor CI, Balogun MR, Mukhtar-Yola M, Ojo OO, Emodi IJ, et al. Mothers and childhood pneumonia: What should the focus of public campaigns be? Nigerian Journal of Paediatrics 2013;40(1):24-29. doi:10.4314/njp. v40i1.4.

36. Eliyas A, Nasir A, Sherali S, Khan I, Khan K, Hashmi F. MOTHERS KNOWLEDGE RELATED PREVENTIVE MEASURE OF PNEUMONIA IN SLUM COMMUNITY, KARACHI, PAKISTAN. Pakistan Journal of Public Health 2018 Dec 11;8(3):156-9.

37. Saeed EA, Awadalla H. Knowledge, Attitude and, Practice among Mothers of Under-Five Children about Acute Lower Respiratory Tract Infections an a Locality in Khartoum Urban Area, Sudan. Journal of Environmental Science and Public Health 2020; 4:455-68.

38. Ndu IK, Ekwochi U, Osuorah CD, Onah KS, Obuoha E, Odetunde OI, Nwokoye I, Obumneme-Anyim NI, Okeke IB, Amadi OF. Danger signs of childhood pneumonia: caregiver awareness and care seeking behavior in a developing country. International journal of pediatrics 2015 Jan 1;2015.

39. World Health Organization. Ending preventable child deaths from pneumonia and diarrhoea by 2025: the integrated Global Action Plan for 
Pneumonia and Diarrhoea (GAPPD). WHO; 2013.

40. Rahimi A, Kassam R, Dang Z, Sekiwunga R. Challenges with accessing health care for young children presumed to have malaria in the rural district of Butaleja, Uganda: a qualitative study. Pharmacy Practice (Granada) 2019; 17:4. doi:10.18549/PharmPract.2019.4.1622. 41. Cardoso MR, Cousens SN, de Góes Siqueira LF, Alves FM, D'Angelo LA. Crowding: risk factor or protective factor for lower respiratory disease in young children? BMC Public Health 2004; 4:1-8. doi:10.1186/1471-2458-4-19.

42. Howie SR, Schellenberg J, Chimah O, Ideh RC, Ebruke BE, Oluwalana C, et al. Childhood pneumonia and crowding, bed-sharing and nutrition:
A case-control study from The Gambia The International Journal of Tuberculosis and Lung Disease 2016;20(10):14051415. doi:10.5588/ijtld.15.0993.

43. ElBasha N, El Rifai N, Draz I, El Kholy A. Contribution of viruses to severe pneumonia in children. Egyptian Pediatric Association Gazette 2013;61(2):73-77. doi: 10.1016/j.epag.2013.07.001.

44. Albanna EA, Ali YF, Elkashnia RA. Vitamin D and LL-37 in children with pneumonia. Egyptian Journal of Pediatric Allergy and Immunology 2010;8(2):81-86.

45. World Health Organization. Training Course on Child Growth Assessment. Geneva, WHO; 2008. 